Research Article

\title{
The Response of Urban Travel Mode Choice to Parking Fees considering Travel Time Variability
}

\author{
Ling Ding ${ }^{1}$ and Xu Yang iD $^{2,3}$ \\ ${ }^{1}$ College of Transportation Engineering, Chang'an University, South Erhuan Middle Section, Xi'an, Shaanxi 710064, China \\ ${ }^{2}$ School of Highway, Chang'an University, South Erhuan Middle Section, Xi'an, Shaanxi 710064, China \\ ${ }^{3}$ Department of Civil Engineering, Monash University, Clayton VIC3800, Australia
}

Correspondence should be addressed to Xu Yang; xyang2@mtu.edu

Received 21 October 2019; Revised 19 May 2020; Accepted 1 July 2020; Published 29 July 2020

Academic Editor: Chao Wu

Copyright (C) 2020 Ling Ding and Xu Yang. This is an open access article distributed under the Creative Commons Attribution License, which permits unrestricted use, distribution, and reproduction in any medium, provided the original work is properly cited.

\begin{abstract}
Increasing automobile use leads to higher costs for traveling associated with emissions, congestion, noise, and other impacts. One option to address this is to introduce high parking charges to reduce the demand for automobile use and encourage the travel mode switch to public transport. To estimate commuters' mode choice behavior in response to high parking fees, commuters from Nanjing completed an individually customized discrete choice survey in which they chose between driving and taking the bus or metro when choices varied in terms of time and cost attributes. Multinomial logit models were used to estimate commuters' responses to high parking charges. In the models, the variability of travel times is considered and analyzed in the stated mode choice models. The results suggest that increases in costs of driving will lead to a great reduction in driving demand. The travel time reliability ratio is 0.50 and the value of each minute late is almost 5.0 times more than the average travel time with the restriction of the maximum allowed delays. The methods used in this study could be adopted to estimate the effect of variable pricing strategies on mode choice responses for different trip purposes. The high value given to travel time variability has implications for transport policy in terms of decision making with respect to new pricing strategies. Moreover, the valuation of travel time savings taken into account in this study would be helpful to better understand the effect of high parking fees.
\end{abstract}

\section{Introduction}

Traditionally, cost and travel time are the two primary variables which affect the choice of travel modes, and travel modal shift in response to parking price has been discussed in the literature [1]. High parking fees in urban central area have been used to shift individuals' travel choices from cars to public transport to mitigate traffic congestion, reduce air pollution, and obtain social economic saving. The parking fees, as part of the cost of travel, play an important role in the decision making of car travelers. The quantitative evaluation of the effect of parking fee on travel mode selection has attracted wide research attention recently. Parking price is an influential factor affecting travel mode behavior and urban traffic policy [2-5]. Travel demand can be effectively reduced in general when a parking charge is applied [6].
Another important effect is the mode choice decision. Existing studies have shown that a large number of respondents would shift their travel modes if parking fees increase [6-8]. The level of traffic congestion of a specific area can be directly influenced by individual travelers' responses to parking policies [4]. A study in South Korea showed that parking fees have a more effective impact on the adjustment of traffic demand than the price of gasoline [9]. Another study found that $38 \%$ of travelers would shift from car to public transport if the daily parking fee increased from 0 to $\$ 6$ in the central business district (CBD) of Portland, Oregon [10]. These studies examined how parking fees affect the choice of travel mode. The travel time and parking charges are key factors affecting decisions on travel mode choice for commuters. Other factors affecting decisions on mode choice, such as socioeconomic characteristics [11-13], 
trip-based characteristics $[13,14]$, and trip purpose $[1,7,12,13,15]$, have also been analyzed.

To date, the focus has been on the development of accurate measures for the examination of behavioral responses to the strategy of increasing parking fees in CBDs. Studies have revealed responses to changes in the price of parking $[2,4,7,12]$. The elasticity of demand for parking also has been studied to analyze the influence of parking fees on choice of travel mode. Studies of commuting trips have derived parking demand elasticity values ranged from -0.1 to -0.6 in the USA $[10,16,17]$. Other studies have focused on non-commuting trips based on stated preference (SP) surveys in which respondents are asked to choose alternative travel modes for hypothetical scenarios [7, 13, 15].

Findings of existing studies have provided practical guidelines for implementing parking pricing. Many cities have expressed great interest in this for the purpose of reducing traffic congestion and air pollution. However, despite the significant achievements that have been made to date, most existing studies do not take account of the travel time variability of individual travelers in their analysis. Modeling of travel time variability and its application in mode choice models is a research area that has recently received attention. It has been reported that different travel modes in mixed traffic have different mean travel times but also different variabilities [18]. Therefore, the present study investigates the effect of high parking fee in CBDs on mode choice considering the effect of travel time variability. A model is developed to estimate the probability that commuters choose to drive or use public transport for the trip to work. The stated choice models with different travel time variabilities and average travel times are then compared.

Travel time variability (TTV) is defined as the random variation in travel time, i.e., the variation in unexplained delay, which is related to random variations in travel time caused by factors that cannot be anticipated or foreseen by a traveler [19]. Since travel time variability is often related to traffic congestion [20], a transport policy aimed at reducing car use such as increasing parking price has the potential of reducing travel times and increasing trip time reliability. The main aim of this paper is to analyze responses to travel mode choice to changes in parking fees considering. We investigate the effect of travel time variability on mode choice. Relying on SP data from hypothetical scenarios for travel mode choices (car, bus, and metro), potential mode shift is estimated if parking fees change. The trip information and the choice decision were obtained based on hypothetical scenarios. The model is then developed to estimate the probability that commuters choose to drive or use public transport for the trip and in turn estimates the variability of commuters' travel times.

This paper contributes to the literature in two respects. First, it models the relationship between decision making and price and proposes travel mode choice responses to changes in parking fees, and travel time variability and average travel time are also embedded in the stated choice models; second, the average value of travel time for commuters is also estimated.
In this paper, the stated choice model is proposed first and the travel time variability and average travel time in different models are reported. Next, trip and SP data for hypothetical scenarios are collected. Then, model results are analyzed. The time distribution and commuters' responses to parking price change are discussed. Next, the differences in the model with travel time variability and average travel time are discussed. Finally, the findings are summarized and conclusions are drawn.

\section{Research Approach}

The objective of this paper is to predict the responses of travel mode choice to parking price changes taking into account travel time variability. The price elasticities are estimated using predictive models. The aggregate travel mode shift from car to public transport with high parking fees is estimated for CBDs based on a case study of Nanjing, China.

2.1. Model Specification. A multinomial logit (MNL) model was utilized to predict the decision of travel mode choice. Based on assumptions of random utility theory, the utility $\left(U_{i j}\right)$ function for an individual $i$ when choosing alternative $j$ is composed of a deterministic component $\left(V_{i j}\right)$ and random errors $\left(\varepsilon_{i j}\right)$. The values given to early and late arrivals are estimated by the schedule delay function approach [21-23]. Travel time variability assumes that travelers have to make their decisions (mode choice, route choice, etc.) in uncertain circumstances [24]. In other words, they are not able to predict the exact travel time before the trip. If the utility function is expressed in linear relation, the deterministic component of travel utility is expressed as

$$
V_{i j}=\alpha_{j}+\beta_{j}^{T} T_{i j}+\beta_{j}^{V} \mathrm{TTV}_{i j}+\beta_{i}^{P} P_{i j}+\beta_{i}^{C} C_{i j}+\gamma Z_{i},
$$

where $T_{\mathrm{ij}}$ is the average travel time of mode $j$ for individual $i$; $\mathrm{TTV}_{i j}$ is the variability of travel time; $P_{i j}$ is the cost of the alternative $j$ for individual $i$; $C_{i j}$ is the comfort level of alternative $j$ for individual $i$; and $Z_{i}$ are the socioeconomic characteristics of individual $i$, including income, age, etc. $\alpha_{j}$, $\beta_{j}^{T}, \beta_{j}^{V}, \beta_{i}^{P}, \beta_{i}^{C}$, and $\gamma$ are parameters to be estimated.

A MNL model was utilized to estimate the stated choice. In the MNL model, $\varepsilon_{i j}$ obeys a Gumbel distribution. Therefore, the probability that the mode $k$ is chosen by individuals can be calculated as

$$
P_{k}=\frac{e^{V_{k}}}{\sum_{j \in J} e^{V_{j}}},
$$

where $V_{k}$ is the deterministic component of utility for travel mode $k$.

2.2. Stated Preference Experiment. Both revealed preference (RP) and stated preference (SP) data were collected from the stated preference survey in this study. The survey which targeted travelers to the CBD of Nanjing on home-to-work commuting trips was conducted in July 2016, and the RP part asked about the latest trip to the CBD including travel time, trip cost, and comfort. The SP questionnaire sought the 
choices for hypothetical scenarios. We hypothesized that the destinations of commuters were not flexible. However, we assumed that individuals may change their departure time to offset possible delays in their trip. The respondents to the SP survey were residents of Nanjing.

Because the correspondents were people living in Nanjing, most were familiar with the alternative travel modes characterized by various costs, travel times, possible delays, and differing levels of comfort. Therefore, the impact due to unfamiliarity with the hypothetical choices was marginal. The choice set comprised three modes, each of which was characterized with the cost (ticket or vehicle fuel costs plus the parking fee), average travel time (the time needed from home to the workplace), variability in travel time due to unexpected congestion, and comfort. As reported in previous studies, the alternatives can be defined by three attributes: average travel time, travel time variability, and travel cost $[25,26]$. These three attributes were taken into account in the SP survey. However, the choice set in studies $[25,26]$ is composed of two alternate routes and the comfort of the two choices was assumed to be the same. As stated above, the choice set in the present study included driving a car, or taking the bus or the metro, and the comfort of driving a car and taking public transport is different. Therefore, the comfort level was considered based on the definition of alternatives in previous studies. In 2015, a change in parking fees occurred in the Nanjing CBD. Drivers needed to pay for on-street parking and underground parking, which resulted in an increase in the hourly rate for parking. The response of individuals to this new parking price was studied. The travel time variability in the experiment was designed based on an empirical questionnaire [27-29].

The questionnaire in the RP/SP survey started with respondents' previous trips to the Nanjing CBD. The questionnaire included questions about some travel attributes: travel purpose, travel mode, travel time, travel cost (fuel cost and parking charge for car travel, fare for transit travel), and comfort. In the SP portion, respondents' travel mode choices with respect to hypothetical scenarios were investigated. Figure 1 shows an example of the choice presented for a scenario. The SP survey collected 378 valid questionnaires from individual commuters to the CBD area of Nanjing. Because six different scenarios were presented in the questionnaire, the total number of responses was actually $378 \times 6=2268$. In other words, we received 378 revealed observations and 2268 stated observations from this questionnaire survey. We took $50 \%$ of the observations as the training data and all the observations as the validation dataset. Additional details about the survey, questionnaire methodology, and the calculation of travel time variability can be found in another study [26].

\section{Results and Discussion}

Two-thirds of the respondents were married, with an average age of 32. Most of the respondents (77.4\%) paid the parking fee themselves for their trips, while the other $22.6 \%$ stated that their employers paid all or part of the parking fee. The gender distribution was reasonably balanced, with 55.7\% male and $44.3 \%$ female respondents. Distribution by household income ranged widely with about $17.6 \%$ on high incomes (over $¥ 200,000$ per year) and $11.7 \%$ on low incomes (less than $¥ 50,000$ per year). More than $76 \%$ of the respondents were employed. Table 1 shows the reported household annual income and occupation. A high proportion of the commuters whose household income is relatively high (more than $¥ 100.000$ ) reported that they had good jobs (such as institution staff or self-employed).

The maximum possible delay within which commuters may arrive at the workplace without penalty (such as a decrease in their wages or change of job position) was also asked in the questionnaire. The data in Table 2 show that most commuters reported that they would face some penalty for being late for work. Even for employers who allowed late arrival, the maximum delay was 10 minutes.

In terms of the maximum delay of arrival at the workplace without penalty, only $0.3 \%$ of the metro users stated that they do not need to pay a penalty if the delay is more than 20 minutes.

3.1. Estimation of Travel Mode Choice Behavior. Travel cost, average travel time, travel time variability, and comfort are the variables in the stated choice model. The MNL regression model was used to investigate the effect of various factors on travel mode choice decisions. The travel time variability in the model is the standard deviation of travel time, and the results are shown in Table 3. The maximum likelihood method was used to perform the estimation as described by McFadden (1973). The cost and average travel time coefficients were negative, as expected. According to the $t$-test (absolute is higher than 1.96), the cost and average travel time are statistically significant at 5\% level in the model, reflecting that cost and average travel time show a significant effect on mode choice. An increase in cost negatively impacts the utility of cars; as expected, an increase in cost also negatively impacts transit mode utilities. The coefficient of comfort is positive, as expected, indicating that comfort has positive effects on total utility. In other words, the total utility increases with an increase in comfort. Note that comfort and travel time variability were of low significance (absolute of $\mathrm{t}$-statistic $<1.96$ ) at $5 \%$ level in the model. This means that comfort shows a positive but little effect on mode choice, and travel time variability is negatively correlated with mode choice and statistically nonsignificant.

In the models, travelers' utility decreased with increasing parking fee if there was no significant difference in other factors, such as travel time. This mean-variance approach analyzed the effect of travel time variability by calculating the reliability ratio of the standard deviation coefficients to the average travel time. A value of 0.50 was obtained in our study, which is similar to the result reported by [30], who found a value of 0.55 for trips to and from work.

In addition to the trip characteristics, travelers' socioeconomic status may also affect their decisions. Therefore, socioeconomic factors such as household income have a direct impact on modal choice as explanatory variables. According to the questionnaire, the socioeconomic variables 
Please choose OPTION A, OPTION B or OPTION C $(\sqrt{ }$ in $\square)$

\begin{tabular}{lcc}
\hline OPTION A $\square$ & Average travel time: 23 minutes & OPTION C $\square$ \\
\hline Average travel time: 18 minutes & You have the same probabilities of arriving: & You have the same probabilities of arriving: \\
You have the same probabilities of arriving: & 2 minutes before your desired arrival time & 2 minutes before your desired arrival time \\
6 minutes before your desired arrival time & 4 minutes after your desired arrival time & 1 minutes before your desired arrival time \\
1 minutes before your desired arrival time & 1 minutes after your desired arrival time & At the desired arrival time \\
2 minutes after your desired arrival time & 2 minutes after your desired arrival time & 2 minutes after your desired arrival time \\
7 minutes after your desired arrival time & The cost of the trip is $¥ 1.60$ & The cost of the trip is $¥ 6.1$ \\
The cost of the trip is $¥ 1$ & The comfort of this trip is 7 & The comfort of this trip is 9 \\
The comfort of this trip is 6 & &
\end{tabular}

FIgURE 1: Example of choice presented for one scenario (option (A) bus; option (B) metro; and option (C) car).

TABLE 1: Sample characteristics: occupation and income.

\begin{tabular}{lccccc}
\hline \multicolumn{3}{c}{ Occupation } & \multicolumn{3}{c}{ Household income (year) } \\
Categories & Cases & $\%$ & RMB & Cases & $\%$ \\
\hline Institution staff & 74 & 19.5 & Under 50,000 & 44 & 11.6 \\
Students & 57 & 15.1 & $50,000-100,000$ & 133 & 35.2 \\
Self-employed & 39 & 10.3 & $100,000-200,000$ & 134 & 35.4 \\
Service staff & 112 & 29.6 & Over 200,000 & 67 & 17.8 \\
Enterprise worker & 85 & 22.5 & & & \\
Retired person & 7 & 1.9 & & & \\
Others & 4 & 1.1 & & & 100 \\
Total & 378 & 100 & Total &
\end{tabular}

TABLE 2: Restriction: maximum delay of arrival at workplace without penalty.

\begin{tabular}{lcc}
\hline Maximum possible delay & Cases & $\%$ \\
\hline No fixed entry time & 59 & 15.5 \\
Less than 10 minutes & 214 & 56.7 \\
$10-14$ minutes & 63 & 16.7 \\
$15-19$ minutes & 41 & 10.8 \\
$20-24$ minutes & 1 & 0.3 \\
$25-29$ minutes & 0 & 0.0 \\
More than 30 minutes & 0 & 0.0 \\
Total & 378 & 100 \\
\hline
\end{tabular}

in the model are the age and income of the commuters. Table 4 presents the results for the model which added socioeconomic factors and restrictions. The estimation results show that older commuters with high incomes are more likely to drive to work, which is consistent with the findings of previous studies $[31,32]$. The restriction of a maximum allowed delay suggests that the value of late time is almost 5.0 times higher than the average travel time.

Values of travel time savings are calculated as the ratio of the estimated coefficients for time to the monetary cost. According to the results in Table 4, the value of travel time saving is $¥ 40.6 / \mathrm{h}$. This value is relatively higher than the average salary. There is an important reason which can explain the higher estimation: the value of travel time in congestion is usually perceived to be higher than that in free-flowing traffic $[25,33]$. However, it is still relatively low compared with the value of travel time in developed countries. The average value of time varied is $30.16 € / \mathrm{h}$ in European countries [34]. The effect
TABle 3: Estimated results (Mode 1).

\begin{tabular}{lcc}
\hline Variable & Coefficient & $t$-test \\
\hline Constant-bus & 0.307 & 2.27 \\
Constant-metro & 1.420 & 1.66 \\
Cost & -0.136 & -2.55 \\
Average travel time & -0.110 & -2.39 \\
Travel time variability & -0.055 & -1.74 \\
Comfort & 0.087 & 1.31 \\
Observations & & 1323 \\
Log likelihood & \multicolumn{2}{c}{-1042.69} \\
McFadden R-squared & \multicolumn{2}{c}{0.294} \\
\hline
\end{tabular}

of travel time variability on travel is revealed by the value of schedule delay, which is calculated according to $\beta_{\mathrm{SD}} / \beta_{\text {cost }}$. The value of scheduled delay includes the value of scheduled delay early and the value of scheduled delay late in theory, expressed by the cost per hour for early arrival and per hour for late arrival $[35,36]$. The value of travel time variability is $¥ 28.9 / \mathrm{h}$ for car users which expressed average value of schedule delay. The value is much less than the result which is $¥ 78.5 / \mathrm{h}$ for air passengers in a paper by [37]. The results showed that the travel time value of air passengers based on personal willingness to pay is about $¥ 30 / \mathrm{h}$ higher. Small also explained that the value of time is very high when going to the airport [36].

In order to validate the proposed models, the predicted results for mode choice were compared with the observed results for four groups with different incomes in Figures 2(a)-2(d). As this figure shows, for each group of individuals, most of the predicted mode choices are the same as the investigated results. Furthermore, the average absolute difference between the investigated and the predicted accuracy was also calculated using the following formula:

$$
Y=\frac{1}{n} \sum_{i=1}^{n} \mu_{i},
$$

where $Y$ is the absolute prediction accuracy; $n$ is the total number of investigated passengers; $i$ is the serial number of a given passenger; and $\mu_{i}$ is the decision value, which is 1 if the predicted mode is the same as the investigated mode; otherwise, it is 0 .

According to the calculation above, the predicted error is $26.7 \%$ in terms of all the travelers. Considering differences in 
TABLE 4: Estimated results with socioeconomic factors and restrictions (Model 2).

\begin{tabular}{lcc}
\hline Variable & Coefficient & $t$-test \\
\hline Constant-bus & -0.374 & -3.30 \\
Constant-metro & 0.820 & 1.98 \\
Cost & -0.170 & -2.78 \\
Average travel time & -0.115 & -2.45 \\
Travel time variability & -0.082 & -2.02 \\
Comfort & 0.007 & 0.03 \\
Income_car & 2.33 & 2.69 \\
Age_car & 1.23 & 1.86 \\
Maximum delay $\leq 10$ mins & -0.576 & -2.64 \\
Observations & & 1324 \\
Log likelihood & & -962.01 \\
McFadden R-squared & & 0.359 \\
\hline
\end{tabular}

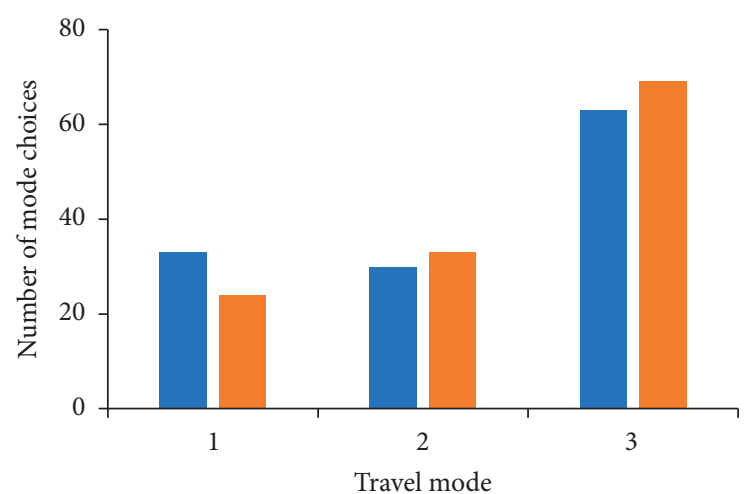

- Predicted

- Actual

(a)

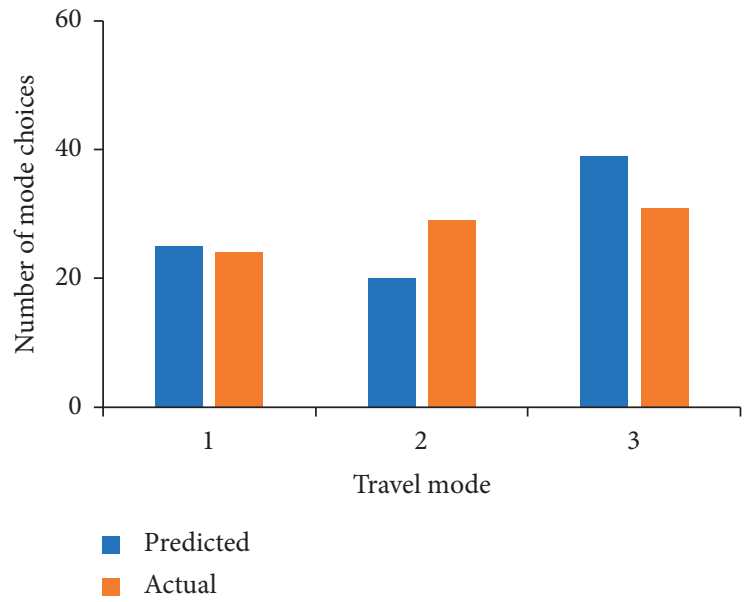

(c)

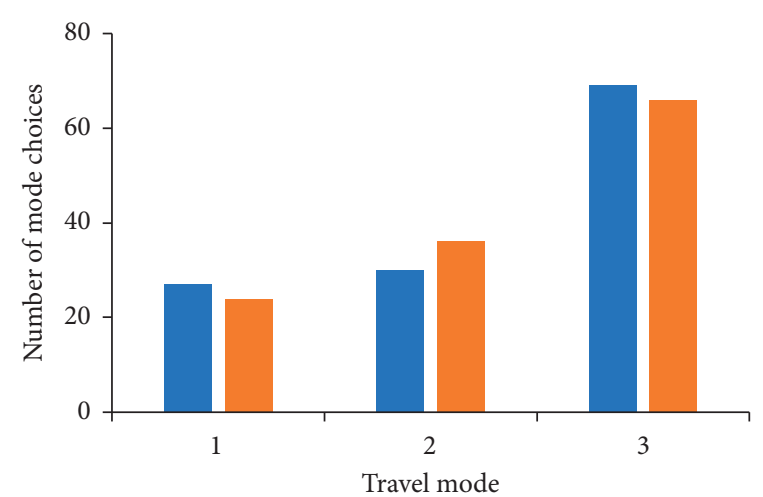

- Predicted

- Actual

(b)

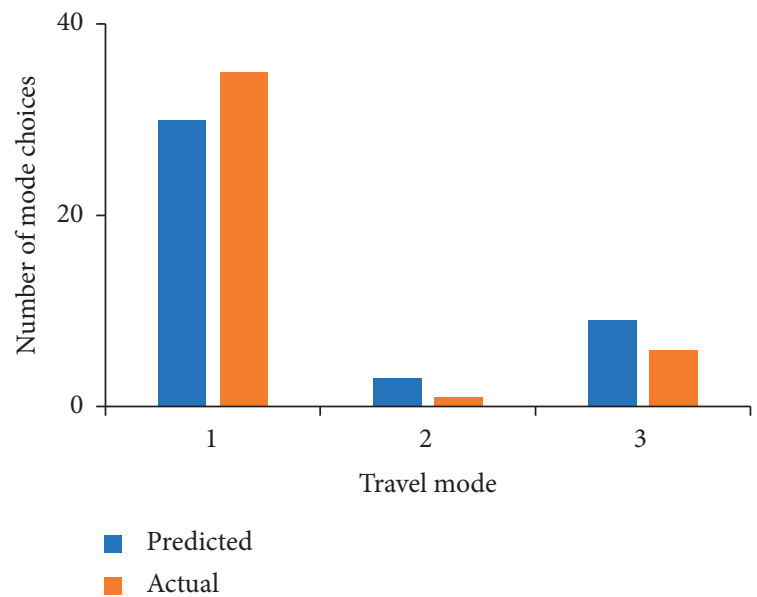

(d)

FIgURE 2: Comparison of predicted and observed numbers of mode choice. (a) Income 1. (b) Income 2. (c) Income 3. (d) Income 4.

income groups, the number of predicted mode choice for each mode was compared with the observed results based on Model 2 (Table 4) in Figure 2. Therefore, the accuracy of prediction for each income group is $73.8 \%$ for group 1 , $76.2 \%$ for group $2,71.4 \%$ for group 3 , and $70.9 \%$ for group 4 . It also can be observed that the choice of car is overestimated for lower income groups. In this paper, the mode was chosen based on the hypothesis that each family has at least one car, which is the main reason why the number of cars was overestimated.

The misestimated data were analyzed separately, as shown in Figure 3 and Table 5. Most incorrect car choices were mispredicted as metro journeys, and all incorrect bus choices were mispredicted as metro journeys. In general, metro use was greatly overestimated. Several reasons may have caused the mispredictions. In addition to the 


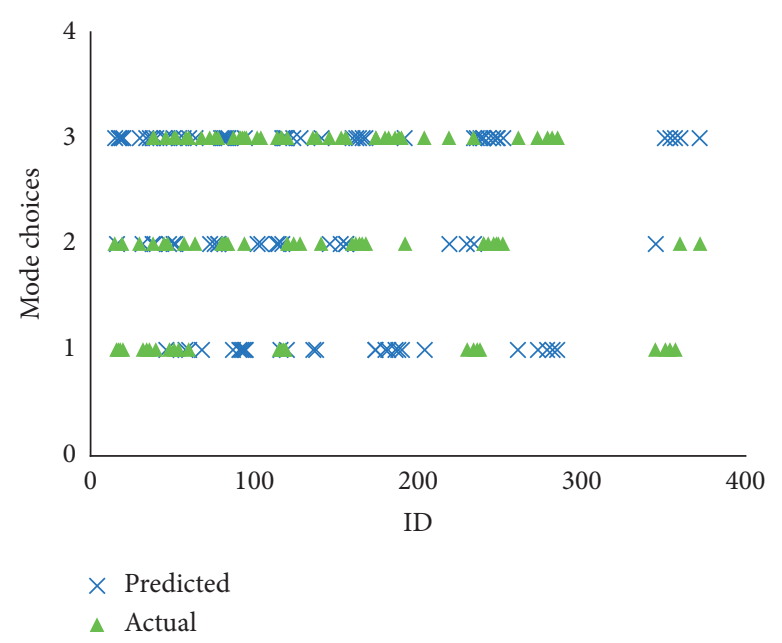

(a)

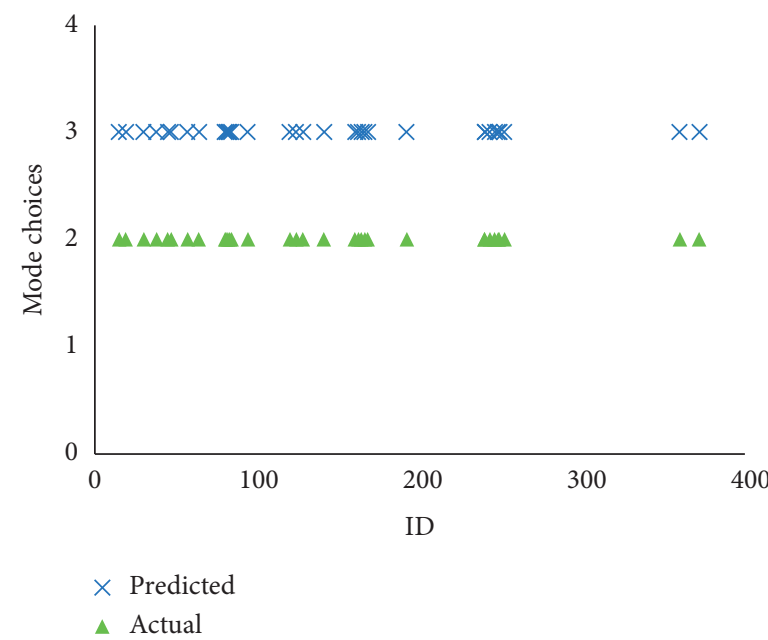

(c)

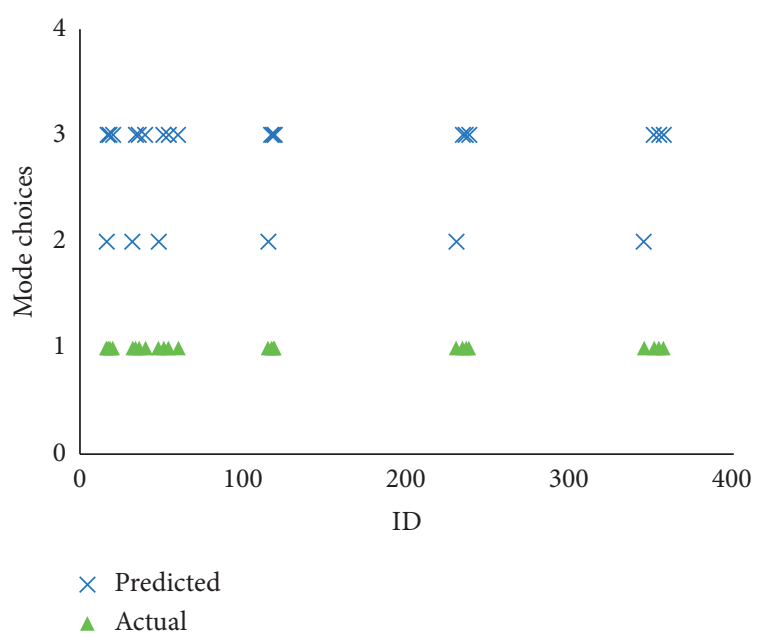

(b)

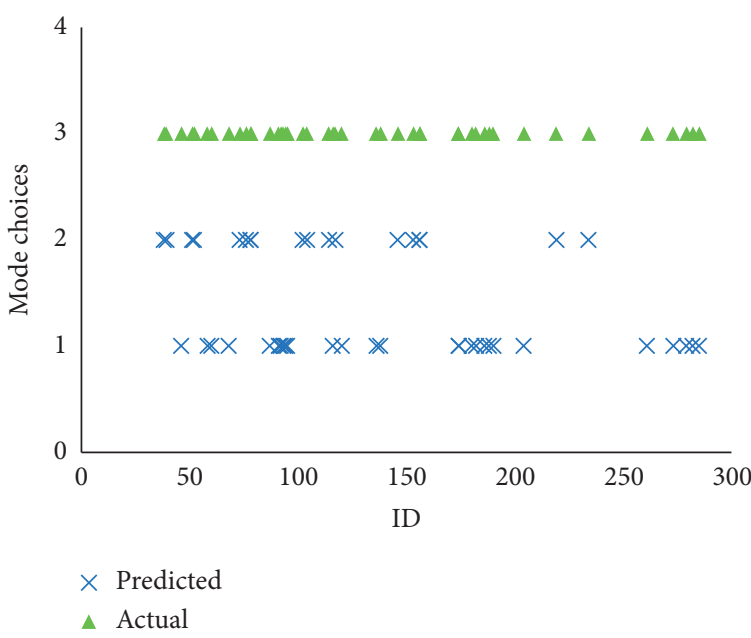

(d)

Figure 3: Misestimation of each mode. (a) Whole. (b) Car. (c) Bus. (d) Metro.

TABLE 5: Misestimation of each mode.

\begin{tabular}{lccc}
\hline & Car & Metro & Bus \\
\hline Car & & 18 & 6 \\
Metro & 26 & & 19 \\
Bus & 0 & 33 & \\
\hline
\end{tabular}

hypothesis of car ownership, another potential cause of error was the availability of a certain travel mode to a person.

3.2. Discussion on Modal Shift to High Parking Fees. On the basis of the above discussion of the two MNL models of mode choice, Model 2 was selected to predict mode shift with the change of parking fees. The mode choice probabilities for three travel modes were $26.2 \%, 24.6 \%$, and $49.2 \%$, respectively. Table 6 shows the effect of parking cost on mode choice probability.

Table 6 shows that a 25\% increase in parking charge reduces the probability of traveling by car from $26 \%$ to $17 \%$. On the other hand, the introduction of a $50 \%$ increase in
TABLE 6: Effect of high parking cost on mode choice probability.

\begin{tabular}{lccc}
\hline $\begin{array}{l}\text { Increased parking cost (based on respondents' } \\
\text { existing parking cost) }\end{array}$ & \multicolumn{3}{c}{ Mode share (\%) } \\
& Car & Bus & Metro \\
\hline 0 & 26.2 & 24.6 & 49.2 \\
$25 \%$ & 17.5 & 26.6 & 55.9 \\
$50 \%$ & 11.9 & 28.4 & 59.7 \\
$75 \%$ & 7.1 & 30.3 & 62.6 \\
$100 \%$ & 6.3 & 31.4 & 62.3 \\
\hline
\end{tabular}

parking charges reduces the driving share to $12 \%$, which corresponds to a total reduction of driving demand of $55 \%$. A $100 \%$ increase in parking charges leads to a $20 \%$ decrease in probability of commuting by car. At the same time, the probability of commuting by metro increases from $49 \%$ to $60 \%$. The probabilities of driving with different parking fees are plotted in Figure 4.

The MNL model found a $26 \%$ probability of driving with current parking costs and a decrease in probability of a commuter choosing to commute by car as the parking cost increases in the Nanjing CBD. This finding indicates that 


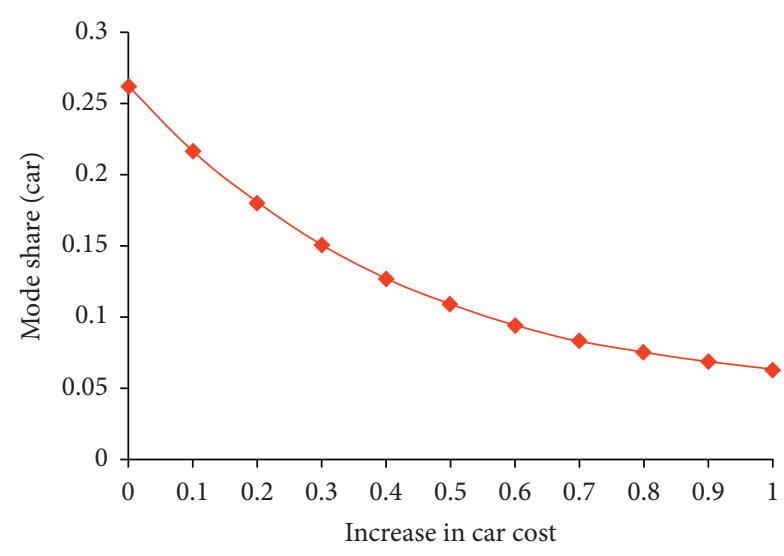

(a)

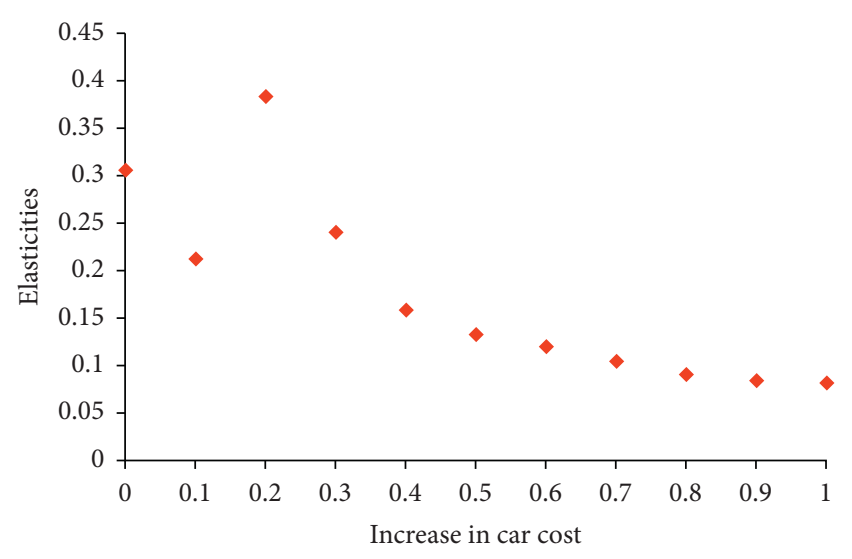

(b)

FIgURE 4: Effect of high car cost on mode choice probability. (a) Mode share (car). (b) Elasticities.

expensive parking has a significant effect on a commuter's choice of driving versus taking public transport, which is supported by empirical work [10]. The elasticity was calculated as follows:

$$
E=\frac{\Delta_{P}}{\Delta_{p p}}
$$

where $\Delta_{P}$ is the change ratio in probability and $\Delta_{p p}$ is the change ratio in parking price.

The elasticities are the percentage change in probability that commuters choose a certain mode with a $1 \%$ change in price. Approximate point elasticities of demand can be provided for travel by car in response to parking price. Figure 4 shows the elasticities for the whole sample. In the case of elasticities (Figure 4(a)), an increase in parking cost results in a decrease in the probability of choosing car travel. In terms of the magnitude, the highest sensitivity of demand occurs when parking fees increase by $20 \%$. According to the results presented in Figure 4(b), it is more elastic when the increase in parking fees is less than $60 \%$. In other words, commuters will change mode from driving to other modes even when the parking cost increases slightly. Further, the results suggest that some individuals will always choose driving to work even if very high parking charges (more than 60\% increase) are introduced. The elasticity here refers to the price elasticity of car use, which is similar to the price elasticity of parking volume (EPV) in the research by Lehner and Peer [38]. If the decrease of parking volume is converted all into the mode choice change (from car use to public transport), the price elasticity of car share is the same with the price elasticity of parking volume. In the study [38], price elasticities which were calculated independently from the generalized costs of travel increase (in absolute terms) if parking prices increase. The parking costs and other travel-related costs might affect the parking price elasticity. No distinction is made between the parking price and travel-related cost in our paper, which means that parking price elasticities are likely to differ across this hypothesis.

The prediction of parking cost elasticity was slightly lower than that in previous studies [39, 40]. Parking charges can reduce congestion to a satisfactory level [6]. Empirical findings show that the effects of parking fees often cause a modal shift to other transport modes [41]. However, after an increase of travel cost to a certain extent, no matter how much the cost increases, the reduction of car share is very limited, and the price elasticity tends to be flat, as shown in Figure 4. Simply increasing the cost of parking cannot ease congestion. To mitigate this situation, parking cash-out has been suggested as an effective and efficient policy to reduce single occupancy car commuting trips [42]. Results indicate that, regardless of model specifications, parking cash-out has a negative and significant effect on the probability of private car choice. Further research could take into account not only the potential effect on mode choice, but also the possible compensation if a traveler gives up a car trip. This calls for a SP survey to capture the implications of the cash-out policy or other price policies (such as parking price, road price, etc.).

\section{Summary and Conclusions}

This study provides an inexpensive method to estimate commuters' responses to high parking charges taking into account travel time variability. Results are presented for changes in commuters' market share for three modes. The elasticities of demand for a mode (car) with different changes in parking costs are also provided. The methods described in this study can be adopted to estimate the effect of different pricing strategies on mode choice responses for different trip purposes. Some general conclusions can be drawn as follows:

Parking charges have a significant effect on travel mode choice, and higher parking charges can reduce the demand for car travel.

The high value given to travel time variability has implications for transport policy in terms of decision making with respect to new pricing strategies.

Any policy on solving congestion and balancing mode structure should take into account the valuation of travel time savings. The value of travel time is 
overestimated because the travel time spent in congestion is usually valued at a higher rate than that in free-flowing situations.

With moderate parking charges, the metro is more attractive than buses, indicating that governments should emphasize the level of comfort and travel time reliability of public transport. Only short travel with less variability attracts drivers to public transport. The survey indicated that commuters will select public transport if high quality services (i.e., metro without transfers) can be provided. Parking charges are able to shift commuters from car travel to public transport when accompanied with transit system improvements. In addition, it should be noted that while this study takes the total cost (fuel and parking) as the main factor affecting mode choice, the detailed components of parking fees were not mentioned to the respondents, which may have made the response biased in some cases. The authors would like to investigate this in the future.

\section{Data Availability}

The data are not publicly available due to privacy restrictions. However, the data supporting the findings of this study are available from the corresponding author upon request.

\section{Disclosure}

The results and findings of the study reflect the opinions of the authors, but not necessarily of those of the financial supporter.

\section{Conflicts of Interest}

The authors declare that there are no conflicts of interest regarding the publication of this paper.

\section{Acknowledgments}

The authors would like to acknowledge the financial support of the Fundamental Research Funds for the Central Universities, CHD (no. 300102210118).

\section{References}

[1] T. Litman, Parking Management Comprehensive Implementation Guide, Victoria Transport Policy Institute, Victoria, Canada, 2011.

[2] B. P. Feeney, "A review of the impact of parking policy measures on travel demand," Transportation Planning and Technology, vol. 13, no. 4, pp. 229-244, 1989.

[3] E. Verhoef, P. Nijkamp, and P. Rietveld, "The economics of regulatory parking policies: the (im)possibilities of parking policies in traffic regulation," Transportation Research Part A: Policy and Practice, vol. 29, no. 2, pp. 141-156, 1995.

[4] G. Marsden, "The evidence base for parking policies-a review," Transport Policy, vol. 13, no. 6, pp. 447-457, 2006.

[5] J. K. Brueckner and S. F. Franco, "Employer-paid parking, mode choice, and suburbanization," Journal of Urban Economics, vol. 104, pp. 35-46, 2017.
[6] G. Albert and D. Mahalel, "Congestion tolls and parking fees: a comparison of the potential effect on travel behavior," Transport Policy, vol. 13, no. 6, pp. 496-502, 2006.

[7] D. A. Hensher and J. King, "Parking demand and responsiveness to supply, pricing and location in the Sydney central business district," Transportation Research Part A: Policy and Practice, vol. 35, no. 3, pp. 177-196, 2001.

[8] R. EsPino, J. de Dios Ortúzar, and C. Román, "Understanding suburban travel demand: flexible modelling with revealed and stated choice data," Transportation Research Part A: Policy and Practice, vol. 41, no. 10, pp. 899-912, 2007.

[9] S. Lee, Y. H. Lee, and J. H. Park, "Estimating price and service elasticity of urban transportation demand with stated preference technique: case in Korea," Transportation Research Record: Journal of Transportation Research Board, vol. 1839, no. 1, pp. 167-172, 2007.

[10] D. B Hess, "Effect of free parking on commuter mode choice: evidence from travel diary data," Transportation Research Record: Journal of the Transportation Research Board, vol. 1753, no. 1, pp. 35-42, 2001.

[11] D. A. Tsamboulas, "Parking fare thresholds: a policy tool," Transport Policy, vol. 8, no. 2, pp. 115-124, 2001.

[12] E. E. Vaca, Traveler Response to Transportation System Changes, Transportation Research Board, Washington, DC, USA, 2005.

[13] J. A. Kelly and J. P. Clinch, "Influence of varied parking tariffs on parking occupancy levels by trip purpose," Transport Policy, vol. 13, no. 6, pp. 487-495, 2006.

[14] A. Kazemi, A. A. Kordani, and B. Mirbaha, "Effect of on-street parking pricing on motorists' mode choice," Proceedings of the Institution of Civil Engineers-Municipal Engineer, vol. 172, no. 2, pp. 1-10, 2017.

[15] Y. Shiftan, "Responses to parking restrictions: lessons from a stated preference survey in Haifa and their policy implications," World Transport Policy And Practice, vol. 5, no. 30-35, 1999.

[16] D. Gillen, "Effects of parking costs on urban transport modal choice," Transportation Research Record: Journal of the Transportation Research Board, vol. 637, no. 46-51, 1977.

[17] Z. Peng, K. J. Dueker, and J. G. Strathman, "Residential location, employment location, and commuter responses to parking charges," Transportation Research Record: Journal of the Transportation Research Board, vol. 1556, no. 1, pp. 109118, 1996.

[18] E. Durán-Hormazábal and A. Tirachini, "Estimation of travel time variability for cars, buses, metro and door-to-door public transport trips in Santiago, Chile," Research in Transportation Economics, vol. 59, pp. 26-39, 2016.

[19] M. Fosgerau, K. Hjorth, C. Brems, and D. Fukuda, Travel time variability, definition and valuation, DTU Transport, Lyngby copenhagen, 2008.

[20] S. Peer, C. C. Koopmans, and E. T. Verhoef, "Prediction of travel time variability for cost-benefit analysis," Transportation Research Part A: Policy and Practice, vol. 46, no. 1, pp. 79-90, 2012.

[21] R. B. Noland, K. A. Small, P. M. Koskenoja, and X. Chu, "Simulating travel reliability," Regional Science and Urban Economics, vol. 28, no. 5, pp. 535-564, 1998.

[22] K. A. Small, R. Noland, and X. Chu, Valuation of Travel-Time Savings and Predictability in Congested Conditions for Highway User-Cost Estimation, Transportation Research Board, Washington, DC, USA, 1999.

[23] R. B. Noland and J. W. Polak, "Travel time variability: a review of theoretical and empirical issues," Transport Reviews, vol. 22, no. 1, pp. 39-54, 2002. 
[24] I. Österle, W. Gort, and A. Weiss, "Forecasting and valuing travel time variability for cost-benefit analysis," Road \& Transport Research: A Journal of Australian and New Zealand Research and Practice, vol. 26, pp. 21-33, 2017.

[25] K. Small, R. Nolan, X. Chu, and D. Lewis, Valuation of TravelTime Savings and Predictability in Congested Conditions for Highway User-Cost Estimation, Transport Research Board, Washington, DC, USA, 1999.

[26] J. Asensio and A. Matas, "Commuters' valuation of travel time variability," Transportation Research Part E: Logistics and Transportation Review, vol. 44, pp. 1074-1085, 2008.

[27] M. Beaud, T. Blayac, and M. Stéphan, "The impact of travel time variability and travelers' risk attitudes on the values of time and reliability," Transportation Research Part B: Methodological, vol. 93, pp. 207-224, 2016.

[28] W. Kou, X. Chen, L. Yu, Y. Qi, and Y. Wang, "Urban commuters' valuation of travel time reliability based on stated preference survey: a case study of Beijing," Transportation Research Part A: Policy and Practice, vol. 95, pp. 372-380, 2017.

[29] M. A. P. Taylor, "Fosgerau's travel time reliability ratio and the Burr distribution," Transportation Research Part B: Methodological, vol. 97, pp. 50-63, 2017.

[30] I. G. Black and J. G. Towriss, Demand Effects of Travel Time Reliability, Centre for Transport Studies, Cranfield Institute of Technology, Cranfield, England, 1993.

[31] S. J. Cutler and R. T. Coward, "Availability of personal transportation in households of elders: age, gender, and residence differences," The Gerontologist, vol. 32, no. 1, pp. 77-81, 1992.

[32] M. Outwater, B. Sana, N. Ferdous, and B. Woodford, Characteristics of Premium Transit Services that Affect Choice of Mode, TCRP, washington, DC, USA, 2014.

[33] P. A. L. Abrantes and M. R. Wardman, "Meta-analysis of UK values of travel time: an update," Transportation Research Part A: Policy and Practice, vol. 45, no. 1, pp. 1-17, 2011.

[34] L. Zamparini and A. Reggiani, "Freight transport and the value of travel time savings: a meta-analysis of empirical studies," Transport Reviews, vol. 27, no. 5, pp. 621-636, 2007.

[35] K. A. Small, "The scheduling of consumer activities: work trips," The American Economic Review, vol. 72, no. 3, pp. 467-479, 1982.

[36] K. A. Small, "Valuation of travel time," Economics of Transportation, vol. 1, no. 1-2, pp. 2-14, 2012.

[37] X. Bai, Z. Yang, and W. Zeng, "Value of time for air passengers accessing to airports," Journal of Transport Information and Safety, vol. 37, no. 3, pp. 128-136, 2019.

[38] S. Lehner and S. Peer, "The price elasticity of parking: a metaanalysis," Transportation Research Part A-Policy and Practice, vol. 121, pp. 177-191, 2019.

[39] G. Jong, A. Schroten, H. Van Essen, M. Otten, and P. Bucci, Price Sensitivity of European Road Freight Transport - towards a Better Understanding of Existing Results, A report for Transport \& Environment, Delft, The Netherlands, 2010.

[40] G. d Jong, "Freight service valuation and elasticities," Modelling Freight Transport, vol. 1, pp. 201-227, 2014.

[41] R. W. Willson, "Estimating the travel and parking demand effects of employer-paid parking," Regional Science and Urban Economics, vol. 22, no. 1, pp. 133-145, 1992.

[42] C. Evangelinos, S. Tscharaktschiew, E. Marcucci, and V. Gatta, "Pricing workplace parking via cash-out: effects on modal choice and implications for transport policy," Transportation Research Part A: Policy and Practice, vol. 113, pp. 369-380, 2018. 